culosis give also clinical manifestations of disease, older children overcome the primary taberculous infection, the more probably the older they are at the time of the infection, without showing more pronounced symptoms of disease.

The prognosis of tuberculosis developed in the several years becomes better from year to year. According to an approximate calculation, the mortality from fresh tubersulosis in the several periods is as follows:
1. First year $\quad \ldots \quad \ldots \quad \ldots 70$ per cent.

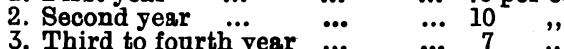

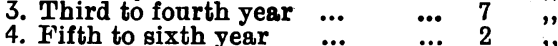

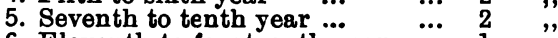
6. Eleventh to fourteenth year ... 1 ,"

It is, therefore, clear that tuberculous morbidity decreases from year to year, although the incidence of tuberculous infection increases from year to year.

The statistics regarding the incidence of tuberculosis among the children of Vienna obtained by means of tuberculin reaction are confirmed by post.mortem results in recent years. Since the autopsy of children of over 6 years has been made with special attention to the probable existence of a tuberculous focus, an almost equally great frequency of tuberculosis in Vienna has been determined by autopsy as by the tuberculin test on the living patient. If in former years the statistics obtained by autopsy as to the incidence were much lower, this is explained by the fact that the examination was not sufficiently searching.

It must be specially emphasized that the figures obtained by Monti and myself refer only to the poorer population of Vienna. Probably in the wealthier popula. tion a much lower percentage of positive tubercalin reac tion would be obtained than is the case in the poorer classes. In the case of the well-to.do open pulmonary taberculosis-the only source of tubercalosis in childhood -is not only much more rare than in the case of the poor, but the wealthy protect themselves mach more carefully from every infection.

The question now is whether the figures obtained by Monti and myself in Vienna are applicable to other towns as well. I think they are. If Ganghofer obtained lower figares in Prague than Monti and myself in Vienna, this is explained by the fact that the cutaneous reaction does not reveal all taberculosis. The "Stich" reaction-that is, the local subcataneous reaction-must also be employed if every case of taberculosis is to be detected. That the frequency of tuberculosis is approximately as great in other large towns as in Vienna is supported by a recent publication by Nothmann, who gives almost the same tigures for Düsseldorf as .Monti and myself for Vienna. One may assume the same figures with regard to the incidence of taberculosis in childhood in all the larger towns as I now present with regard to Vienna. In the country the incidence is probably rather less, and above all more irregular, than in the town.

Since the majority of persons develop tuberculosis in childhood we cannot be surprised that tabercalous sym. ptoms are so common in childhood. Indeed, taberculosis in children usually offers very different symptoms to those of adults.

Conclusions.

1. The majority of persons become infected by tuberculosis in childhood.

2. The frequency of tuberculous infection increases from year to year, whilst tuberculous morbidity-that is, the frequency of manifest tuberculous disease-decreases from year to year.

3. Tuberculosis is very commonly latent, producing no symptoms; this is especially so if the infection dates from the third or fourth year.

4. The prognosis of taberculosis in childhood becomes more favourable the older the person is at the time of the first infection.

THE extra.parliamentary commission which is drawing up administrative regulations under the French old age pensions law will not report before November, so that the law cannot come into force until this time next year. It is estimated, however, that $£ 1,800,000$ will be required in 1911-that is to say, about one-third of the total estimated expenditure for a year.

\section{ADDRESS ON}

\section{THE PREVENTION OF MORTALITY FROM} PELVIC OPERATIONS.*

By H. MACNAUGHTON.JONES, M.D., M.CH., M A.O., PRESIDENT OF TEE OBSTETRICAL AND GYNAECOLOGICAL SECTION OF THE ROYAL SOCIETY OF MEDICINE.

\section{[ABstract.]}

[Dr. Macnadghton-Jones discussed the increased responsibility attached to operative interference through the perfection of modern preventive methods in diagnosis, preoperative measures, technique, and the post-operative management of the patient, entering separately into several points in each. The pernicious effects of delay in diagnosis were emphasized, as also the incalcalable harm done by the present-day resort to boomed remedies, involving the postponement of seeking professional advice, and the danger arising from the reliance on the part of the public on popular medical literature which takes the form of some indispensable Household Medical Cookery Book, compiled on the "Every Man His Own Lawyer" principle. The exceptions in which a difficulty was found in making an early diagnosis were summarized. The pleading was not so much for a definite differentiation of the nature of conditions, as an early recognition of an abnormality, which, in the great proportion of cases, either at the time requires, or in the near futare will demand, surgical interference. Vain temporizing, or the lulling of a patient into a sense of false security added in various ways to the magnitude, complications, and consequent risks of the future operation.]

How (he asked) is not life lost and operative risk increased by dallying with appendical disease, ectopic gestation, taberculous and gonorrhoeal salpingitis, ovarian blood cysts, adnexal carcinoma, streptococcus and $B$. coli abscess of the tube or ovary, early carcinoma of the portio, exhausting haemorrhages, fibromitis, degenerations, adhesions, and the renal and cardiac complications of myoma of the uterus? The delusions that the ovaries are not frequently invaded by malignant disease; that myomata are not often the sources of fatal degenerations, or that the menopause is a time when expectancy is justified, and which explains various pathological conditions, of which the patient will be relieved when the climacteric has ceased, are myths of the past. Now we know that jast in proportion to the years after 50 the risks and fatality from myomata are increased by necrosis and malignant degenerations.

The immediate antecedents of an operation might well be divided into the surroundings, and the preparation of the patient. Either we are ourselves the dupes of a fanciful, faddish system, and a Will.o'-the-wisp hunt after an impossible ideal, or we are striving to secure on scientific and assured grounds the greatest immunity from risk of those who place their lives in our hands. If we are justifed in the steps we insist on as essential to effect the latter in our pablic hospitals and their costly theatres, with the refinements of aseptic precautions in tiled walls, mosaiced floore, with special drainage, filtered air, tem. perature regulators, sterilizers, pedalled sinks and dressing holders, airtight cases and glass operating tables-ought we not to come as near them as possible in our cottage hospitals and nursing homes?

There are cases in which, short of letting the patient die from her ignorance, we should absolutely refuse to operate, or before consenting, by the plainest speaking place the responsibility on her and her friends. It is not for as to condone a line of conduct which we believe increases enormously the risk to life.

There might be in every large town self-supporting sanatoriums, so farnished and equipped as to meet the requirements of the better.off classes, or the more modest or unpretentious demands of the poorer, and the charges should be regulated accordingly. The control might be municipal, but this need not exclude the right of private enterprise in the erection and conduct of the institation. Each sanatorium would have at least two operating theatres, and the necessary preparation, anaesthetizing, photographic, and radiogr $\rightarrow$ phic rooms, with one general

* Delivered to the Maidstone Division of the South-Eastern Branch of the British Medical Association, June 23rd, 1910. 
sterilizing department. Built on the corridor principle with lifts, the patients could be easily carried from the bed to the theatre with the least possible disturbance or exposure. They would have their own private medical attendant and select their own consultants. Each sanatorium would be under the immediate control of medical director and assistant, and a joint medical and lay committee be responsible for the administration. All might be subject to State inspection. This is but a skeleton idea. It is the principle on which Loeve's Sanatorium in Vienna was conducted when I visited it. The details are easily worked out. It bas these advantages - there is no mixing up of charity and legitimate expenditure of public money for the poor, with the indirect use of the same by those who are not ashamed to avail of it, and who have no right to it; it obviates the dislike of many who, shrinking from availing of a hospital, yet cannot afford the luxury of the private home; it leaves the medical attendant free to operate himself if he elect to do so, and to attend his patient.

[The questions of preoperative rest, attention to the bowel, mouth, teeth, and diet, were each separately discussed. The scopolamin morphine-chloroform method of anaesthesia (with or withont oxygen) administered by the Harcourt regulator was advocated in certain cases. The advantage of ether over chloroform as an anaesthetic in secondary operations for sepsis, or in acute suppurative septic states, he considered was established by the results recorded by Harold Stiles and Beesley of acetone production, and the experiments on anaphylaxis by Besredka. Spinal anaesthesia and infiltration anaesthesia had each its proper place.]

With regard to asepsis, quite apart from scrupulous attention to surroundings, appliances, the precautions of the operator, assistants, nurses, the sterilization of the clothing of the patient, and the material and the appliances used, as well as the final toilet and subsequent dressings, there were other matters quite as important in the effort to arrive at an ideal asepsis. This included the careful dealing with imprisoned septic fluids and exposed tissues, or any accidental bowel communications, the complete arrest of hromorrhage, and the use when absolutely necessary, and only then, of drainage. Operation by the clack was to be deprecated. There were exceptional occasions when time came in as the most important element for consideration. But a modern pelvic operation, in complete haemostasis, the anticipation of future perilous adhesions by careful covering of pedicles and raw surfaces, the examination of suspicious tissues or organs, entirely exclude any justification for " hurry," a word we should not at any cost admit into our surgical vocabulary.

In an instance of a large collection of putrid pus involv. ing a probable septic infection of an extensive wound, after closure of the peritoneum and the applicetion of formalin solution ( 1 in 1,000 ) to the infected surfaces, he had resected the edges for their entire length, also inserting a suprapubic rubber drain, with a most successfal result. Paquelin's cautery might be used instead of the formalin. The rubber drain is preferable to the gauze, save in the case where a Mikulicz pack is required, or in vaginal drainage. Saline flushing of the pelvis and abdominal cavity, save in very exceptional cases, is better avoided. Careful and gentle mopping out with ganze, wet with weak formalin solution, is preferable. It were well to remember the immediate and remote dangers axising Irom overlooking residual septic products in cases of arrested pregnancy when the uterus was emptied by ovam forceps or curettage. Such are easily overlooked, and hence the necessity for douching while maintaining dilata. tion of the canal, and repeating the curettage if the temperature and nature of the discharge called for it.

Shock, either daring or after operation, is not so often heard of now with our present technique and the improved administration of anaesthetics. The recent advances in the employment of continuous saline irrigation of the rectum, or proctoclysis (J. B. Murphy), the employment of " infandibulin" by intramuscalar injection (Blaïr Bell), and the use of the principle "tyramine" obtained from ergot, afford most important means of dealing with shock, paresis of the borvel, and haemorrhage. The Fowler position, aided by proatoclysis and suprapubic drainage, was an invaluable adjunot to the treatment of post-aperative peritonitis. Cyllin is a highly valuable remedy in gastro- intestinal complications. It is a most powerful bactericide, especially of the B. coti; is well borne, assists in checking sickness and in the disinfection of the bowel. I have used it habitually for some years as a post-operative remedy in these cases.

No hard and fast rule can be laid down for the resort to morphine. The administration of a nightly dose of atropine I $\frac{1}{\delta} \sigma$ and $\frac{1}{6} m$ of morphine bas often an admirable effect in controlling sickness and inducing a restful night. It may be stated as a general rule that morphine is better avoided, but a woman's temperament is a powerful asset in her recovery account, and an important item either on the credit or debit side of our operative balance sheet. As to diet and movement, I do not believe in preoperative starvation. We do not now follow the old practice of Lawson Tait, and give nothing save hot water for so many hours after operation, nor do we keep any longer the patient on her back for days; still, in medio tutissimus ibis and festina lente are good surgical mottoes, and w.e are safest in feoling our way, first with fluid, and then with light, easily assimilable nourishment, and not too soon taking the risks of movement out of bed and walking.

\section{ON THE PRESENCE OF SUGAR IN HEALTHY URINE AS A SOURCE OF THE OSAZONE REACTION.}

\author{
BY
}

F. W. PAVY, M.D., and H. W. BYWATERS, D.Sc., LL.D., F.R.S., Pн.D., F.I.C.

The communication of Dr. William Russell in the BrITISH MEDICAL Journar of July 2nd, p. 5, on "The "Pancreatic Reaction' in Abdominal Disease," bas led us to send for pablication the subjoined notes, drewn from an un. published paper written about two years ago, and founded upon experimental work.

The question of the presence of sugar in normal urine was, at a period now long since past, the subject of a warm and somewhat prolonged discussion, in which one of us (F. W. P.) took an active part on the affirmative side. It was contended that the cupric oxide reducing power, recognizable by means of the ammoniated cupric test, was due, at least in part, to the presence of free sugar, and this free sugar was, as a matter of fact, found to be susceptible of separation by precipitation with lead acetate and ammonia, and afterwards to undergo alcoholic fermenta. tion in contact with yeast.

The introduction of the phenylbydrazine test by Emil Fischer bas since furnisbed the means of forcibly corroborating the conclusion previously arrived at. An osazone is always readily obtainable from the extracted sugar derived from a moderate quantity of urine; and, funther, as will be seen from what follows, the preliminary separa. tion of the sugar is, in many cases, unnecessary, inasmuch as the amount of it that is present in normal urine is sufficiently large to permit of osazone crystals being obtained by direct treatment with phenylhydrazine.

It is advantageous, however, to treat the urine in the first place with lead acetate to remove certrin of the urinary constituents which seem to prevent the osazone from assuming a crystalline form; $20 \mathrm{ccm}$. of the urine are shaken with $5 \mathrm{c} \mathrm{cm}$. of a 25 per cent. solution of neutral lead acetate and the resulting precipitate removed by filtration. The excess of lead is then got rid of by adding 2 grams of powdered sodium sulpbate, boiling, cooling in a stream of cold water, and filtering off the precipitated lead sulphate; $15 \mathrm{c} \mathrm{cm}$. of the filtrate are now added to 2 grams of sodium acetate, 0.8 grams of phenylhydrazine hydrochloride, and $15 \mathrm{c} \mathrm{cm}$. of acetic acid $(B . P$.), contained in a mall flask, and the mixture is boiled under a refiux condenser for fifteen minutes. The liquid is filtered while still hot into a test tube and allowed to stand for some hours. The small deposit which collects at the bottom of the tube will, in most cases, be found on microscopic examination to consist of the characteristic sheaves and rosettes of osazone crystals.

The same results follow if the neutral lead acetate be replaced, as in Cammidge's pancreatic reaction, by 4 grams of powdered tribesic lead acetate, provided sufficient acotic acid be added to give an acid reaction to the mixture. In 